\title{
Pengaruh Kuliah Konseptualisasi dengan Peta Konsep pada Awal Pelatihan Keterampilan Medik terhadap Nilai OSCE Akhir Blok
}

\author{
B.P. Suryosubianto, Yayi Suryo Prabandari, Ova Emilia \\ Fakultas Kedokteran Universitas Jenderal Ahmad Yani
}

\begin{abstract}
Background. OSCEis known as a skills examination method with high level of objectivity and reliability. Many efforts explore to increase OSCE achievement. Increasing the underlying knowledge of medical skills prior to a skills training proven to improve the skills achievement. A lecture delivered using concept maps, are considered better than the conventional lecture.

Objective. To find out that a lecture using concept maps before splinting skills training will increase theOSCE scores. Methods. A quasi-experimental post test only study was conducted among 151 students of the Faculty of Medicine, General Achmad Yani University studying trauma at the fourth semester. The 74 students of the experiment group got a trauma lecture using concept maps, the 77 students of the control group got a trauma lecture without concept maps. The result of the splinting OSCE scores of the two groups were compared and statistically analyzed.

Results. The average value of the OSCE score of the experiment group was significantly higher (89.10) than the control group (84.93). There were no differences in OSCE score among different gender, grade point average value, and the expertise of the instructors.

Conclusion. Lecture in trauma before splinting skills training using the concept map that explains on the conceptualization (i.e. indication, contraindication, and how to prevent, identify and treat the splinting complications), will increase the score of OSCE. Demonstration of cases according to the theme of the subject involving a group of students, will enhance student understanding of the lecture topics.
\end{abstract}

Keywords: lecture with concept maps and demonstration, skills training, OSCE.

\section{ABSTRAK}

Latar Belakang. OSCE sudah ditetapkan sebagai cara ujian keterampilan klinik yang obyektif dan terandal. Berbagai metode dipakai untuk meningkatkan pencapaian OSCE. Meningkatkan pemahaman mengenai pengetahuan yang mendasari keterampilan medik yang akan dilatihkan, dapat meningkatkan hasil pelatihan keterampilan. Bentuk kuliah yang disampaikan menggunakan peta konsep yaitu piranti pembelajaran pengetahuan yang dianggap lebih baik dari kuliah konvensional.

Tujuan. Mengevaluasi dampak kuliah trauma dengan peta konsep pada awal pelatihan keterampilan pembidaian mahasiswadalam meningkatkan nilai OSCE mahasiswa.

Metode. Penelitian ini adalah riset kuantitatif menggunakan rancangan kuasieksperimental post test only. Subjek penelitian adalah mahasiswa semester keempat di Fakultas Kedokteran Unjani. Pada akhir blok dermatomuskuloskeletal, dibandingkan hasil OSCE 74 orang mahasiswa kelompok perlakuan yang mendapat kuliah trauma dengan peta konsep tentang indikasi, kontra-indikasi, serta cara mencegah, mengidentifikasi, dan mengatasi penyulit tindakan membidai dengan hasil OSCE 77 orang mahasiswa kelompok kontrol yang kuliahnya tanpa peta konsep. Hasil. Nilai OSCE rata-rata kelompok perlakuan lebih tinggi secara signifikan $(89,10)$ dibandingkan dengan nilai OSCE kelompok kontrol $(84,93)$. Tidak terdapat perbedaan hasil OSCE menurut jenis kelamin, nilai indeks prestasi kumulatif, maupun kepakaran instruktur.

Korespondensi: suryosubianto@yahoo.com HP: 08122013663 
Kesimpulan. Kuliah trauma pada awal pelatihan pembidaian yang menjelaskan dengan peta konsep tentang konseptualisasi, yaitu indikasi, kontraindikasi, serta cara mencegah, mengidentifikasi serta mengatasi penyulit pembidaian, akan meningkatkan nilai OSCE keterampilan membidai khususnya pada kelompok perempuan. Demonstrasi kasus sesuai dengan tema pokok bahasan kuliah melibatkan kelompok mahasiswa, akan meningkatkan pemahaman mahasiswa terhadap topik kuliah.

Kata kunci: kuliah dengan peta konsep dan demonstrasi, latihan keterampilan, OSCE.

\section{PENDAHULUAN}

Pada pendidikan kedokteran dasar, pembelajaran pengetahuan, keterampilan, maupun sikap sama pentingnya. ${ }^{1,2}$ Standar Kompetensi Dokter Indonesia (SKDI) yang disahkan Konsil Kedokteran Indonesia mencantumkan komunikasi efektif, keterampilan klinis, danlandasan ilmiah ilmu kedokteransebagai tiga area di dalam tujuh kompetensi yang wajib dikuasai lulusan. ${ }^{3}$ Deskripsi keterampilan profesional dikemukakan oleh Bond \& Spurritt, yaitu meliputi konsep kompetensi, ekspertisi, pertimbangan, dan seni sampai merupakan urutan tindakan kompleks yang telah menjadi rutin melalui latihan dan pengalaman sehinggadapat dilakukan hampir otomatis. Praktek yang terampil secara otomatis ini menjadi faktor penyebab utama, mengapa pembelajaran keterampilan menjadi suatu tantangan yaitumenjelaskan dan mengajarkannya tidak mudah. ${ }^{4}$ Jenis-jenis keterampilan klinik yang diajarkan kepada mahasiswa, ditentukan sejak awal rancangan blok-blok pembelajaran. ${ }^{5}$

Pembelajaran dan penilaian keterampilan kliniktelah dilakukan pada blok pembelajaran tahap Sarjana Kedokteran di Fakultas Kedokteran Universitas Jenderal Achmad Yani (FK-Unjani). Pada awal implementasi kurikulum berbasis kompetensi, ada keterampilan yang dilatihkan tanpa didahului penjelasan tentang konseptualisasi, yaitu indikasi, kontra-indikasi, serta bagaimana mencegah, mengidentifikasi, dan mengatasi penyulit suatu tindakan medik.Peningkatan pengetahuan yang mendasari suatu keterampilan, menggunakan kuliah powerpoint disertai peta konsep, sebagaimana dilakukan oleh Dermidover dkk. ${ }^{6}$ Usaha peningkatan pengetahuan ini diharapkan akan dapat meningkatkan penguasaan keterampilan, yang dibuktikan dengan meningkatnya hasil OSCE akhir blok.
Penelitian ini bertujuan untuk menguji perbedaan hasil ujian keterampilan kelompok yang diberi penjelasan menggunakan powerpoint dengan peta konsep tentang indikasi, kontra-indikasi, serta cara mencegah, mengidentifikasi, dan mengatasi komplikasi, dibandingkan dengan kelompok yang diberi penjelasan menggunakan powerpoint tanpa peta konsep.

\section{METODE}

Penelitian ini memakai pendekatan kuantitatif dengan rancangan kuasi-eksperimental post test only. Satu angkatan mahasiswa FK-Unjani semester keempat yang akan mengikuti pelatihan keterampilan medik teknik membidai pada blok dermatomuskulo-skeletal (blok pertama dalam semester tersebut), mendapat pengetahuan mengenai pembidaian pada kuliah trauma muskuloskeletal, menggunakan naskah powerpoint. Mahasiswa angkatan tersebut dibagi menjadi dua kelompok yaitu kelompok kontrol dan perlakuan. Pembagian kelompok didistribusikan secara sistematik berdasarkan IPK sehingga diperoleh kelompok yang setara. Pemilihan kelompok kontrol dan perlakuan dilakukan dengan undian.

1. Kelompok kontrol, mendapat kuliah tentang trauma yang disampaikan menggunakan naskah powerpoint tentang traumatanpa peta konsep.

2. Kelompok perlakuan, mendapat kuliah tentang trauma menggunakan naskah powerpoint dengan peta konsep yang menjelaskan mengenai trauma serta indikasi dan kontra-indikasi membidai; cara prevensi, identifikasi, dan mengatasi penyulit membidai. 
Penelitian ini telah disetujui oleh Komisi Etik Penelitian Kedokteran dan Kesehatan Universitas Gadjah Mada no. KE/FK/562/EC tanggal 9 September 2011.

\section{HASIL DAN PEMBAHASAN}

Penelitian ini melibatkan 151 mahasiswa semester empat FK Unjani yang sedang menjalani Blok Dermatomuskuloskeletal, terdiri dari 97 orang perempuan dan 54 orang laki-laki. Pada kelompok perlakuan sebanyak 74 mahasiswa yang mengikuti kuliah dengan peta konsep sebelum pelatihan keterampilan, serta kelompok kontrol yakni 77 mahasiswa yang mengikuti kuliah dengan powerpoint tanpa peta konsep.

Pada kelompok perlakuan dan kontrol nilai rata-rata OSCE mahasiswa perempuan konsisten lebih tinggi dibanding mahasiswa laki-laki. Meskipun demikian perbedaan tersebut tidak bermakna secara statistik.

Tabel 1. Deskripsi nilai OSCE kelompok perlakuan dan kontrol

\begin{tabular}{lcc}
\multicolumn{1}{c}{ Deskripsi } & Perlakuan & Kontrol \\
Nilai minimal & 58 & 48 \\
Nilai maksimal & 100 & 100 \\
Rata-rata & 89,10 & 84,93 \\
Standar deviasi & 9,258 & 10,25 \\
\hline
\end{tabular}

IPK mahasiswa tidak berhubungan dengan hasil OSCE keterampilan pembidaian. Uji korelasi Pearson (interval) menunjukkan korelasi lemah $(0,305 ; \mathrm{p}>0,05)$ dan tidak bermakna, yang berarti tidak ada hubungan IPK dan nilai OSCE pembidaian.

\section{Pengaruh kepakaran instruktur}

Pada kelompok eksperimen maupun kelompok kontrol, masing-masing terdapat satu orang instruktur pakar, yaitu seorang dokter spesialis bedah saraf instruktur ATLS, dan seorang dokter bedah umum yang pernah mengikuti kursus ATLS.Bila hasil OSCE kelompok mahasiswa yang latihan keterampilan membidainya diberikan oleh instruktur pakar tersebut dibandingkan dengan kelompok mahasiswa yang instrukturnya dokter umum.

Berdasarkan data di atas, nilai rata-rata kelompok eksperimen lebih besar dibandingkan dengan kelompok kontrol.Uji normalitas data nilai OSCE ternyata tidak memiliki distribusi normal, maka Uji Mann-Whitney digunakan untuk menguji perbedaan nilai OSCE. Pada analisis tersebut, $\mathrm{p}=0.007$ sehingga dapat ditarik kesimpulan bahwa terdapat perbedaan antara nilai OSCE pada kelompok perlakuan dan kelompok kontrol, dengan nilai OSCE yang lebih tinggi pada kelompok perlakuan.

Pencapaian nilai ujian OSCE pembidaian menurut jenis kelamin mahasiswa, ditunjukkan pada tabel 2.

Tabel 2.Hasil analisis independent t-testnilai OSCE pembidaian pada kelompok perlakuan dan kelompok kontrol berdasarkan jenis kelamin

\begin{tabular}{|c|c|c|c|c|c|c|}
\hline \multirow{2}{*}{ Kelompok } & Laki-laki & Perempuan & \multirow{2}{*}{$\begin{array}{c}\Delta \\
\text { Mean }\end{array}$} & \multirow{2}{*}{$t$} & \multirow{2}{*}{$\mathrm{p}$} & \multirow{2}{*}{ CI 95\% } \\
\hline & mean $\pm \mathrm{SD}$ & mean $\pm S D$ & & & & \\
\hline $\begin{array}{l}\text { Perlakuan } \\
(\mathrm{lk}+\mathrm{pr}=74)\end{array}$ & $\begin{array}{c}86,4 \pm 11,9 \\
(n=23)\end{array}$ & $\begin{array}{c}90,3 \pm 7,6 \\
(\mathrm{n}=51)\end{array}$ & $-3,9$ & $-1,69$ & 0,09 & $-8,45-0,69$ \\
\hline $\begin{array}{l}\text { Kontrol } \\
(\mathrm{lk} \cdot \mathrm{pr}=77)\end{array}$ & $\begin{array}{c}83,8 \pm 10,8 \\
(n=30)\end{array}$ & $\begin{array}{l}85,6 \pm 9,9 \\
(\mathrm{n}=47)\end{array}$ & $-1,8$ & $-0,77$ & 0,44 & $-6,65-2,93$ \\
\hline $\begin{array}{l}\text { Pcrlakuan + Kontrol } \\
(\mathrm{lk}+\mathrm{pr}=151)\end{array}$ & $\begin{array}{c}84,9 \pm 11,3 \\
(\mathrm{n}=53)\end{array}$ & $\begin{array}{l}88,0 \pm 9,1 \\
(\mathrm{n}=98)\end{array}$ & 3,1 & 1,86 & 0,07 & $-6,47-0,19$ \\
\hline
\end{tabular}

(semua dokter umum ini belum pernah mengikuti kursus ATLS), ternyata tidak ada perbedaan hasil OSCE antara kedua kelompok. Sesuai dengan pengalaman penulis sebagai ATLS Course Director, keluhan dari peserta kursus muncul bila kesempatan berlatih keterampilan klinik menjadi berkurang karena instruktur lebih lama membahas teori sehingga alokasi waktu untuk praktik keterampilan kurang dari $80 \%$ dari seluruh waktu 
latihan. Kesempatan tiap peserta berlatih dan mendapat umpan balik langsung tampaknya memiliki pengaruh paling dominan.

\section{Menjaga kesetaraan materi pada penelitian eksperimen}

Untuk menjaga kesetaraan materi pada penelitian eksperimen yang kemungkinan memberikan dampak pada nilai akhir mahasiswa maka dilakukan perlakuan khusus. Pada akhir kuliah, dilakukan demonstrasi kasus trauma oleh empat orang mahasiswa yang memerankan pengelolaan salah satu kasus trauma dari kumpulan skenario pada apendiks kuliah. Sesuai dengan pendapat Emilia $^{7}$ dan Silberman ${ }^{8}$ bahwa untuk meningkatkan keefektifan kuliah maka perlu dilengkapi dengan metode pengajaran lain misalnya dalam penelitian ini menggunakan metode demonstrasi.Demonstrasi dapat dipakai untuk penerapan teori pada contoh kasus, selain juga sekaligus melakukan studi kelompok pada suatu pengajaran terarah.

Sulitnya memperoleh kesetaraan antara dua kelompok yang diperbandingkan pada suatu penelitian di bidang edukasi medik telah dikemukakan oleh Norman \& Schmidt ${ }^{9}$ dan Dolmans ${ }^{10}$. Oleh karena itu sulit dibuktikan bahwa kegagalan atau keberhasilan suatu eksperimen disebabkan hanya oleh satu jenis intervensi. Edukasi sangat mungkin dilakukan di jaringan interaksi sosial yang rumit dan selalu berubah-ubah, sehingga perlakuan yang teracak, hasil yang murni, atau perlakuan yang benar-benar setara tidak akan pernah ada.

Penyebab perbedaan hasil OSCE antara kedua kelompok disebabkan karena perbedaan pada cara menjelaskan tentang prinsip $\mathrm{ABCD}$ pada pengelolaan kasus trauma dan cara menjelaskan indikasi, kontra-indikasi, serta cara mencegah, mengidentifikasi, dan mengatasi penyulit pembidaian bukan hanya pada penggunaan peta konsepnya. ${ }^{11,12}$ Penulis memberi demonstrasi kasus trauma pada akhir kuliah, suatu metode pembelajaran yang memicu pemahaman lebih baik. ${ }^{7,8,13}$ Karena pada demonstrasi tersebut kelompok mahasiswa dilibatkan dengan memainkan peran sebagai tim pengelola kasus trauma, berarti pada demonstrasi tersebut sekaligus dilakukan pula studi kasus, studi berkelompok, dan pengajaran terarah (Emilia, 2006; Silberman, 2006). ${ }^{7,8}$ Meskipun yang langsung terlibat hanya empat orang mahasiswa pengelola kasus simulasi trauma, namun pembelajaran kelompok peserta demonstrasi ini disaksikan oleh seluruh mahasiswa peserta kuliah yang diberi kesempatan bertanya setelah demonstrasi berakhir. Setelah kelompok mahasiswa tersebut melakukan tugasnya, mereka mendapat umpan balik, yaitu tentang bagian yang sudah dilakukan dengan baik, dan bagianbagian yang perlu ditingkatkan serta bagaimana cara melakukannya dengan benar.

Menggunakan konsep Gagné dkk ${ }^{14}$ yang membagi proses pengajar-an menjadi sembilan tahap sebagai tolok ukur pengajaran, dapat dikemukakan hal-hal sebagai berikut:

a. Kuliah interaktif membuka kesempatan untuk mengikuti sembilan tahap pengajaran.

b. Pemanfaatan peta konsep mengacu ke tahap kelima (memberikan arahan pembelajaran) dan tahap kesembilan (menekankan ingatan dan transfer).

c. Melibatkan mahasiswa pada praktik mengelola kasus trauma mengacu ke tahap keenam sampai dengan kesembilan.

Rancangan kuliah yang dipakai menerapkan secara konsisten sembilan langkah pengajaran menurut Gagné dengan penekanan pada arahan pembelajaran serta ingatan dan transfer dengan digunakannya peta konsep. Di pihak kelompok kontrol, tanpa demonstrasi oleh mahasiswa, langkah pengajaran tahap ke-6 sampai dengan ke-8 hilang, dan penekanan untuk retensi dan tansfer pada langkah pengajaran ke-9 menjadi berkurang. ${ }^{14}$

\section{Kontaminasi}

Untuk meminimalkan kontaminasi maka perlakuan menggunakan kuliah parallel terpisah antara kelompok perlakuan dan kontrol. Tetapi pada pelaksanaannya, karena setelah kuliah dengan pokok bahasan trauma usai, kegiatan berikutnya berlangsung di kampus, maka mahasiswa dari kelompok kontrol yang kuliahnya di RS Dustira kembali ke kampus sehingga beberapa orang ikut menyaksikan demonstrasi mengelola kasus trauma dengan panduan peta konsep.

Bila dicermati tanggal pelaksanaan kuliah, tanggal pelatihan keterampilan, dan ujian OSCE, maka didapatkan bahwa jarak antara kuliah dan pelatihan membidai adalah enam hari, sedangkan jarak pelatihan 
ke OSCE adalah 12 hari. Adanya jeda tersebut memungkinkan terjadinyakontaminasi yang tidak dapat sepenuhnya dicegah.

Meskipun kemungkinan terjadinya kontaminasi antara kelompok perlakuan dan kelompok kontrol tidak dapat dicegah sepenuhnya, hasil OSCE kelompok perlakuan lebih baik daripada kelompok kontrol, dan secara statistik perbedaannya bermakna. Karena kelompok perlakuan mendapat kuliah yang mengawali pelatihan menggunakan powerpoint dengan peta konsep yang menjelaskan trauma serta indikasi dan kontra-indikasi membidai; cara prevensi, identifikasi, dan mengatasi penyulit membidai yang disampaikan menggunakan peta konsep, maka kemungkinan perbedaan tersebut terutama disebabkan oleh meningkatnya pengetahuan oleh karena pemahaman yang lebih mendalam dengan pengajaran memanfaatkan peta konsep. ${ }^{15,16,17}$

\section{KESIMPULAN}

1. Kuliah trauma pada awal pelatihan keterampilan pembidaian yang menjelaskan dengan peta konsep disertai dengan demonstrasi kasus meningkatkan nilai OSCE keterampilan membidai.

2. Peningkatan nilai OSCE keterampilan membidai lebih tinggi pada kelompok perempuan dibanding laki-laki.

3. Tidak ada perbedaan nilai OSCE pada mahasiswa yang dilatih oleh instruktur pakar dan instruktur bukan pakar.

\section{SARAN}

1. Perlu dilakukan sosialisasi dan pelatihan pada instruktur dan staf pengajar tentang penggunaan peta konsep dalam pelatihan keterampilan medik.

\section{DAFTAR PUSTAKA}

1. NewbleD \& Cannon R.A handbook for medical teachers $4^{\text {th }}$ ed. Dordr-echt: Kluwer Academic Publishers; 2001.

2. Dent J.A. \& Hesketh, E.A.How to teach in the clinical skills centre. Medical Teacher, 2004; 26(3): 207-10.

3. Konsil Kedokteran Indonesia: Standar kompetensi dokter: Jakarta; 2006
4. Bond $\mathrm{H} \&$ Spurritt D. Learning practical skills. inHiggs, J. \& Edwards, H.Educating beginning practitioners: challenges for health professional education. Butterworth-Heineman, Oxford, 1999:189-94

5. Snellen-Balendong H \& Dolmans D. Block construction. Maastricht: Dept.of Educational Develompent \& Research, Maastricht University; 1999.

6. Demirdover, Yilmaz, Vayvada \& Atabey.Comparison of learning with concept maps and classical methods among medical students.Proc. of the third Int.Conference on Concept Mapping, Helsinki; 2008.

7. Emilia, O. Kuliah interaktif: Naskah ajar Pelatihan Nasional Effective Lecturing. Yogyakarta, BPKFKUGM. 2006

8. Silberman, M.Active training, $3^{\text {rd }}$ ed. Pfeiffer, San Francisco; 2006: 71-95

9. Norman, G.R. \& Schmidt, H.G. Effectiveness of problem-based learning curricula: theory, practice and paper darts. Medical Education, 2000;34: 721728.

10. Dolmans, D.The effectiveness of PBL: the debate continues. Some concerns about the BEME movement. Medical Education, 2003;37: 1129-1130.

11. American College of Surgeons, Committee on Trauma:Preparation for teaching, in ATLS Faculty Manual.Chicago; 2008.

12. Hulsman, R.L., Mollema, E.D., Hoos, A.M., de Haes, J.C.J.M., Donnison-Speijer, J.D; 2004: Assessment of medical communication skills by computer: assessment method and student experiences. Medical Education 2000; 34: 939-45.

13. Bennett MJ \& Ewan CE. How to organize and conduct a demonstration. Medical Teacher 1981; 3(4): $127-130$.

14. Gagné, R.M., Wager, W.W., Golas, K.C. \& Keller, J.M.Principles of instructional design $5^{\text {th }}$ ed. Belmont, Wadsworth /Thomson Learning; 2005: 45-55, 192 207.

15. Akinsanya, C.\& Williams, M: Concept mapping for meaningful learning. Nurse educ. Today, 2004; 24: 4146

16. Novak, J.D.,\& Canas, A.J.(2006): The theory underlying concept maps and how to construct them. www.ihmc.us.

17. Kinchin, I.M.\&Cabot,L.B.An introduction to concept mapping in dental education: The case of partial denture design. Eur J Dent Educ, 2009; 13: 2027. 